\title{
Long-term therapy of chronic non-malignant pain with potent opioids in an active police officer
}

\author{
[Traitement prolongé de douleurs chroniques non cancéreuses avec des opioïdes
}

puissants chez un policier actif]

Peter H.K. Mak Mb CHB FRCA FFARCSI, Siu L. Tsui MB BS MD FANZCA FFPMANZCA, K.F. Jacobus Ng MB CHB FANZCA MBA

Purpose: To report the successful long-term use of methadone and tramadol in treating low back pain in a marine police officer.

Principal findings: The patient sustained a work-related injury having fallen down stairs while on duty in 1990. After multiple operations for a prolapsed L5/SI intervertebral disk, he was first seen at our pain clinic in 1994. Numerous systemic medications, invasive procedures, physiotherapy and psychotherapy were used to treat his pain, but without sustained effect.

Methadone was started in late 1995 and tramadol in 2000. The current maintenance doses are methadone $20 \mathrm{mg}$ and tramadol $200 \mathrm{mg}$, both twice daily. Apart from some initial disruption, the patient was soon able to return to full time work. Regular performance reports from his supervisors have always been excellent.

Conclusion: The use of methadone in this police officer with chronic low back pain has been very successful despite the demanding nature of his job. The controversy surrounding, and further suggestions regarding long-term use of opioid therapy for nonmalignant pain are discussed.

Objectif: Rendre compte de l'usage prolongé efficace de méthadone et de tramadol comme traitement des douleurs lombaires chez un officier de la police maritime.

Constatations principales : Le patient a subi un accident du travail en 1990 en tombant dans un escalier. Après de multiples opérations pour un prolapsus discal à $L 5 / S I$, il s'est présenté à notre service antidouleur en 1994. De nombreux médicaments à action générale, des interventions effractives, de la physiothérapie et de la psychothérapie ont été utilisés sans produire d'effet analgésique durable. La méthadone a été prescrite à la fin de 1995 et le tramadol en 2000. Les doses de maintien courantes sont de $20 \mathrm{mg}$ de méthadone et de 200 mg de tramadol, à prendre deux fois par jour. Mis à part une interruption initiale, le patient est bientôt retourné au travail à temps complet. Les rapports réguliers sur le rendement produits par ses superviseurs ont toujours été excellents.

Conclusion : L'usage de méthadone chez un officier de police présentant des douleurs lombaires chroniques s'est révélé très efficace malgré la nature exigeante de son travail. La controverse entourant l'usage prolongé d'opioïdes pour des douleurs bénignes et des suggestions supplémentaires sont examinées.

\section{Case report}

A 33-yr-old marine police officer was first seen at our pain clinic in 1994 for chronic low back pain. He sustained a L5/S1 prolapsed intervertebral disc injury after falling down stairs while on duty in 1990. Anterior spinal fusion was performed in 1991 but pain relief was moderate and only lasted for a few months. Orthopedic surgeons carried out facet joint injections without success. He was then referred to our pain clinic for further management. At the first visit, his visual analogue pain score (VAS) was 8 (0-10 scale). Physical examination showed severe spasm of his paraspinal muscles and straight leg raising limited to 30 bilaterally. There were no localized tender points or signs of facet joint involvement. He had been off work most of the time for four years and his mood was low. He was particularly bothered by insomnia. His medications included baclofen $10 \mathrm{mg}$ twice a day, diclofenac slow release $100 \mathrm{mg}$ once a day, amitriptyline $25 \mathrm{mg}$ h.s. and nitrazepam $5 \mathrm{mg}$ h.s. An epidural with local anesthetics and steroids was offered but declined due to a previous bad experience with facet joint injection. Physiotherapy was continued

From the Department of Anaesthesiology, Queen Mary Hospital, University of Hong Kong, Pokfulam, Hong Kong.

Present address of correspondence: Dr. Peter H.K. Mak, Department of Anesthesia, Toronto Western Hospital, University Health

Network, 399 Bathurst Street, Toronto, Ontario M5T 2S8, Canada. Phone: 416-603-5118; Fax: 416-603-6494; E-mail:

makphk@yahoo.com

Accepted for publication January 14, 2002.

Revision accepted March 18, 2002. 
without much improvement. Transcutaneous electrical stimulation was useful but pain relief was only temporary. Acupuncture and traditional Chinese herbal treatment were also unsuccessful.

The patient underwent further surgery for spinal stenosis after developing urinary incontinence. Fluoxetine, dihydrocodeine and diclofenac topical gel were then added to his long list of medications. Several discussions took place with the patient and his supervisors in the police force emphasizing that improvement of his condition would be a long and arduous process. VAS at this time was 9-10. Both parties agreed that he should aim for functional improvement as complete pain relief became less likely. Over the next few months, he continued physiotherapy and needed several hospital visits for sudden and severe breakthrough pain requiring im injection of meperidine. Amitriptyline was discontinued and doxepin 75 $\mathrm{mg}$ once a day started. The patient returned to work and could cope with some part-time clerical work.

In late 1995, the pain had worsened and his VAS was 10. Again, after a lengthy discussion with the patient and his supervisors about long-term opioid use, methadone was started at a dose of $5 \mathrm{mg}$ twice daily. Fluoxetine was increased to $20 \mathrm{mg}$ daily. During the next several follow-up appointments, his VAS decreased from 8 to 4 . The dose of methadone was gradually increased over the next three years and settled at $20 \mathrm{mg}$ four times a day. Regular follow-up was required for dose titration. He was seen weekly for the first eight weeks, then monthly for the next ten months. When his symptoms and methadone dosage were balanced at $20 \mathrm{mg}$ four times a day, appointments were scheduled every three to six months. The degree of pain relief, adverse effects and possible cognitive impairment were important outcome measures during this time. A clinical psychologist was invited to provide psychotherapy and group therapy. The patient returned to work full time but his activities required constant supervision because of chronic opioid use. Monthly work reports were sent to our clinic for performance analysis after written informed consent was obtained from the patient. He still required several hospital admissions for breakthrough pain over the next two years and, in addition to his regular doses of methadone, morphine syrup was added during hospitalizations. However, it proved to be too short acting (less than one hour) and was soon discontinued.

In the beginning of 2000 , while on vacation abroad, tramadol $200 \mathrm{mg}$ twice a day was prescribed for exacerbation of pain. This dosage has been unchanged to date but the dose of methadone has been reduced to $20 \mathrm{mg}$ twice a day. Although the patient is no longer allowed to handle firearms, he is still functioning well in the police department, working mainly in the communications' and the training departments. This was challenging work for him, as the training of future police officers requires a high degree of physical activity. The police communications' department also requires clear cognitive function as well as constant vigilance. Despite chronic opioid use, performance reports have shown that the patient was able to return to full time demanding work and continues to be a productive member of society.

\section{Discussion}

Chronic use of opioid analgesia for non-malignant pain has been a controversial subject for many years. ${ }^{1,2}$ Numerous articles have reported successful treatment with opioid therapy but many were of relatively short duration, usually for weeks or months. ${ }^{3}$ One recent article described a two-year follow-up of 40 patients receiving methadone. ${ }^{4}$ Some have stated that a carefully selected group of patients may benefit from opioid use ${ }^{5}$ but with emphasis based on symptomatic relief. Limited information on functional daily activity is available.

The obvious reason for introducing potent opioid therapy is the failure of symptomatic relief after many trials of non-opioid analgesics. Despite numerous successful reports and documentation of safety of chronic opioid use in these patients, ${ }^{6}$ many physicians are still hesitant for fear of tolerance, physical dependence and addiction. ${ }^{7}$ Current opinion however, suggests that this fear is overstated and will only promote unnecessary suffering. ${ }^{8}$ Other adverse effects common to all opioids are nausea, vomiting, constipation, sedation and respiratory depression. However, with meticulous titration of dosage against side effects, these can be minimized and become tolerable and comparable to those in patients with malignant pain. ${ }^{9}$

There are however, other more subtle problems. Long-term opioid therapy may produce an impairment of psychomotor function, particularly in the elderly. ${ }^{10}$ Careful evaluation is needed to monitor the ability to perform daily activities. Numerous different tests of psychomotor function have been described such as the Wisconsin Card Sorting Test, the Verbal Fluency Test and the Pattern and Spatial Recognition Tests. ${ }^{11}$ They can be used in patients who require chronic opioid therapy especially if a clinical psychologist is also involved in patient care. Lack of compliance can also be easily overlooked especially if firm patient selection criteria are not established. ${ }^{12}$

Since there are many potential problems with prescribing long-term opioids, guidelines are necessary. No such guidelines existed in Hong Kong when this 
patient was first seen at our clinic in 1995. Subsequently, in 1996, the Medical Council of Hong Kong published general guidelines for medical practitioners prescribing opioid, benzodiazepine and psychotropic drugs. ${ }^{13}$ However, these simple guidelines were not specifically targeted for patients with chronic non-malignant pain. The Australian Pain Society and the College of Physicians and Surgeons of Ontario in Canada published their guidelines in $1997^{14}$ and $2000^{15}$ respectively. These require a detailed history and physical examination, regular assessment, precise treatment plan and objectives, informed consent (including a written agreement with patients), means to consult other expertise if problems arise and meticulous record keeping. Single prescriber and pharmacy as well as monitoring of compliance e.g., urine and serum drug level testing were also stressed. Overall management of this patient concurred remarkably well with guidelines subsequently published worldwide.

The Australian guidelines suggest that sustained release morphine preparations are the drugs of choice for patients with non-malignant pain. Our patient however, disliked the idea for the fear of being addicted to a 'street-drug'. Literature on the use of methadone is scant. We chose to use it for several reasons. It is a potent opioid with high bioavailability and therefore suitable for oral administration. It has no known metabolites, is relatively inexpensive and has long administration intervals. ${ }^{16}$ As well as its mu and delta receptor agonist activity, it is also known to possess some N-methyl-D-aspartate (NMDA) receptor inhibition. ${ }^{17}$ It has been suggested that the combination of an opioid and a drug with NMDA receptor antagonist properties may improve the level of analgesia and minimize adverse effects. ${ }^{18}$ However, its long half-life with unpredictable pharmacokinetics between individuals may cause delayed toxicity such as excessive sedation and respiratory depression. ${ }^{19}$ Careful titration and observation must be carried out to avoid these.

Tramadol was started while the patient was on vacation abroad. As well as being a centrally acting opioid, tramadol also affects the descending inhibitory pathways and modulates nociception through its inhibition on the reuptake of monoamines such as norepinephrine and selective serotonin receptors (SSRI). ${ }^{20}$ Although a weaker analgesic, its use decreased the consumption of methadone. Fluoxetine is an antidepressant with SSRI activity. Its combination with tramadol, which has serotonergic activity, can therefore precipitate serotonin syndrome with hyperstimulation and seizures. Fortunately, the use of fluoxetine was no longer required and had been discontinued 18 months prior to the introduction of tra- madol. One also has to be careful when introducing tramadol to a patient already receiving high doses of potent opioids as this combination can cause acute opioid withdrawn symptoms. A detailed and informative discussion with our patient showed that he had a good understanding of these drugs before initiation of therapy. At this stage however, it is still too early to recommend the ideal drug, its formulation and the starting and maintenance dosages in this highly heterogeneous group of patients. ${ }^{21}$

As opioids may also cause psychomotor disturbance, we believed that it was essential to receive regular assessment and work reports from his supervisors to allow the patient to return to work. Monthly reports from the marine police headquarters were required during his first year of opioid treatment and quarterly thereafter. This was arranged in advance with informed consent from the patient. One can be more precise in these work reports by including a scoring chart for routine tasks. Such scoring charts can then be used to evaluate patient progress. The police department suspended our patient's use of firearms while on opioid treatment. However, a high degree of physical activity was required from the patient as a training officer and a high level of vigilance and cognitive function for communication duties. Despite the chronic use of methadone at doses of up to $80 \mathrm{mg}$ day $^{-1}$, his performance was judged as excellent by his colleagues and supervisors. Close communication between all parties involved is highly recommended. Existing guidelines do not address the issue of 'monitored return to work' and it may be useful to incorporate this facet into future recommendations. This is especially important when return to full time work is crucial for the patient, financially or otherwise. Overall functional improvement can also be assessed by scoring systems such as the Sickness Impact Profile ${ }^{22}$ and the Multidimentional Pain Inventory. ${ }^{23}$ Together with pain scores, categories like work, ambulation, recreation, sleep pattern, perceived life control and pain behaviour can be examined more objectively.

This case is unique because of the patient's working environment. Police officers (including marine officers) in Hong Kong are constantly involved in drug related crime. We warned our patient that occasional measurement of serum opioid levels would be required if concerns arose about drug compliance. Dose escalation in this group of patients can be relatively common, up to $78 \%$ in one study. ${ }^{4}$ Although pharmacological tolerance may be the reason for progressive increases in dosage, drug abuse remains a possibility. Fortunately, our patient reduced his drug requirement voluntarily. 
In conclusion, this case highlights the successful long-term use of opioids by a police officer with nonmalignant low back pain over the past six years. We emphasized functional improvement and global well being. ${ }^{24}$ Frequent communication with the employer allowed the patient to return to his highly demanding job. The search for an ideal drug in this highly heterogeneous group of patients continues.

\section{Reference}

1 Stein C. Opioid treatment of chronic nonmalignant pain. Anesth Analg 1997; 84: 912-4.

2 Shannon CN, Baranowski AP. Use of opioids in noncancer pain. Br J Hosp Med 1997; 58: 459-63.

3 Moulin DE, Iezzi A, Amireh R, Sharpe WKJ, Boyd D, Merskey $H$. Randomised trial of oral morphine for chronic non-cancer pain. Lancet 1996; 347: 143-7.

4 Taylor WF, Finkel AG, Robertson KR, et al. Methadone in the treatment of chronic non-malignant pain: a 2year follow-up. Pain Med 2000; 1: 254-9.

5 Schofferman J. Long-term use of opioid analgesics for the treatment of chronic pain of nonmalignant origin. J Pain Symptom Manage 1993; 8: 279-88.

6 Portenoy RK, Foley KM. Chronic use of opioid analgesics in non-malignant pain: report of 38 cases. Pain 1986; 25: 171-86.

7 Potter M, Schafer S, Gonzalez-Mendez E, et al. Opioids for chronic nonmalignant pain. Attitudes and practices of primary care physicians in the UCSF/Stanford Collaborative Research Network. University of California, San Francisco. J Fam Pract 2001; 50: 145-51.

8 Collett BJ. Opioid tolerance: the clinical perspective. $\mathrm{Br}$ J Anaesth 1998; 81: 58-68.

9 Zenz M, Strumpf M, Tryba M. Long-term oral opioid therapy in patients with chronic nonmalignant pain. J Pain Symptom Manage 1992; 7: 69-77.

10 Larsen B, Otto H, Dorscheid E, Larsen R. Effects of long-term opioid therapy on psychomotor function in patients with cancer pain or non-malignant pain (German). Anaesthesist 1999; 48: 613-24.

11 Ornstein TJ, Iddon JL, Baldacchino AM, et al. Profiles of cognitive dysfunction in chronic amphetamine and heroin abusers. Neuropsychopharmacology 2000; 23: 113-26.

12 Schulzeck S, Gleim M, Maier C. Morphine tablets for chronic non-tumor-induced pain. Which factors modify the success or failure of a long-term therapy? (German). Anaesthesist 1993; 42: 545-56.

13 Anonymous. Guidelines on the proper prescription and dispensing of dangerous drugs by registered medical practitioners: Medical Council of Hong Kong, 1996.

14 Graziotti PJ, Goucke CR. The use of oral opioids in patients with chronic non-cancer pain. Management strategies. Med J Aust 1997; 167: 30-4.

15 Anonymous. Evidence-Based Recommendations for Medical Management of Chronic Non-Malignant Pain. Reference Guide for Clinicians. The College of Physicians and Surgeons of Ontario, 2000.

16 Ripamonti C, Zecca E, Bruera E. An update on the clinical use of methadone for cancer pain. Pain 1997; 70: 109-15.

17 Mancini I, Lossignol DA, Body JJ. Opioid switch to oral methadone in cancer pain. Curr Opin Oncol 2000; 12: 308-13.

18 Portenoy RK. Current pharmacotherapy of chronic pain. J Pain Symptom Manage 2000; 19: S16-20.

19 Manfredi PL, Gonzales GR, Cheville AL, Kornick C, Payne $R$. Methadone analgesia in cancer pain patients on chronic methadone maintenance therapy. J Pain Symptom Manage 2001; 21: 169-74.

20 Shipton EA. Tramadol - present and future. Anaesth Intensive Care 2000; 28: 363-74.

$21 \mathrm{McQuay} \mathrm{H}$. Opioids in chronic non-malignant pain. There's too little information which drugs are effective and when (Editorial). BMJ 2001; 322: 1134-5.

22 Pollard B, Johnston M. Problems with the Sickness Impact Profile: a theoretically based analysis and a proposal for a new method of implementation and scoring. Soc Sci Med 2001; 52: 921-34.

23 McCracken LM, Spertus IL, Janeck AS, Sinclair D, Wetzel FT. Behavioral dimensions of adjustment in persons with chronic pain: pain-related anxiety and acceptance. Pain 1999; 80: 283-9.

24 Andersen S, Leikersfeldt G. Management of chronic non-malignant pain. Br J Clin Pract 1996; 50: 324-30. 